\title{
Milton Hatoum: um clássico contemporâneo
}

\author{
Marcello Giovanni Pocai Stella* \\ https://orcid.org/0000-0003-2420-0392
}

Nas capas dos livros de Milton Hatoum, editados pela Companhia das Letras, é possível se deparar com um pequeno adesivo redondo de cor amarela, no qual se lê "Um clássico da literatura brasileira contemporânea". Este artigo visa a reconstruir, em perspectiva sociológica, a trajetória desse escritor ${ }^{1}$ e sua consagração, no sentido de esclarecer a posição que ocupa no campo literário.

A partir de referências como Goffman (1981), Sapiro (2014) e Pinheiro Filho (2019), sugiro que a trajetória de Milton Hatoum é marcada, de um lado, pelo esforço de se afirmar como um dos herdeiros principais da grande tradição literária brasileira, inscrevendo-se assim no polo autônomo do campo (Bourdieu, 1996), de circulação restrita; e, de outro, por estratégias voltadas ao sucesso comercial, que poderiam deslocá-lo para o polo heterônomo, de circulação ampliada. Essa aparente contradição relaciona-se, como tentaremos demonstrar, com as lógicas que estruturam diversos campos literários nacionais contemporâneos, como o brasileiro, nos quais o êxito literário e o comercial não são excludentes².

* Universidade de São Paulo, São Paulo, Brasil.

1. As informações coletadas constam de várias entrevistas concedidas pelo autor em veículos de imprensa variados. Boa parte delas está armazenada na página web pessoal do autor: http://www.miltonhatoum. com.br/, consultada em 10/10/2016.

2. Embora Bourdieu tenha definido os campos de produção cultural a partir de sua autonomia crescente em relação aos campos econômico e político, em texto recente (2019), Gisèle Sapiro sugere que o desenvolvimento dos mesmos não seria "teleológico nem linear", podendo ocorrer perda de autonomia na disputa com esses campos dominantes. No meio do século Xx, a literatura se politizaria, em função da 
Segundo Bourdieu (1996), as vendas dos autores clássicos ao redor de 1970 na França seriam caracterizadas em geral pelo insucesso comercial a curto prazo e, após a consagração literária interna ao campo, pelo sucesso comercial a longo prazo. Entretanto, casos como o de Zadie Smith ${ }^{3}$ e seu primeiro livro White Teeth (2000), estudado por Pouly (2016), parecem contradizer essa ordem esperada de acontecimentos. Como podemos explicar sociologicamente esses "best-sellers de qualidade"?

Tal expressão teria sido cunhada por atores do mundo editorial e se referiria a livros com potencial de angariar créditos propriamente literários, alcançando, também, sucesso comercial. Os "best-sellers de qualidade" ou os "clássicos contemporâneos" seriam os livros mais almejados por todo editor, por venderem bem tanto a curto como a longo prazo. Mais ainda, além de granjearem um público mais amplo, tais livros transmitiriam sua legitimidade literária ao editor. Em suma, os “best-sellers de qualidade" disputariam simultaneamente o jogo especificamente literário, atendendo aos seus mecanismos de consagração estéticos, e o jogo do mercado, no qual o marketing e a publicidade seriam essenciais para alavancar vendas imediatas e alcançar o público ampliado (Pouly, 2016).

Passo a examinar neste item a trajetória de Milton Hatoum ${ }^{4}$. Sua família é, predominantemente, de origem libanesa. Sua mãe era católica e o pai muçulmano (fatos que aparecem com destaque em seu primeiro livro, Relato de um certo Oriente). Sua avó libanesa materna estudou num colégio francês em Beirute, e boa parte da família era versada na língua francesa. $\mathrm{O}$ avô paterno de Milton chegou ao Brasil no início do século xx, durante o Ciclo da Borracha e foi para o Acre, onde residiu na cidade de Xapuri e trabalhou como mascate. Após onze anos na Amazônia, retornou ao Líbano, para a capital Beirute.

Motivado pelas histórias escutadas sobre o Brasil, o pai de Hatoum (que também estudou em um colégio francês no Líbano) emigrou, também, ao Brasil. Depois de residir no Acre durante nove anos, foi para Manaus, onde se casou. O estabelecimento definitivo nessa cidade se deu em 1949, onde a família de sua esposa já vivia fazia

Segunda Guerra, e, desde o final desse século, com o surgimento de grandes conglomerados editoriais, se tornaria cada vez mais dependente do mercado. Se essa conjuntura implica perda de autonomia, devemos lembrar que gera possibilidades de profissionalização pelo menos para os autores mais consagrados do campo.

3. Não por acaso, essa autora foi incorporada ao catálogo da Companhia das Letras, desde 2007.

4. A maior parte das informações foi recolhida em entrevistas (Barreto \& Mello, 2007; Gebaly, 2010). Ver também a dissertação de mestrado de Mascagna (2015). 
tempo (seus pais eram donos de importante casa de comércio na cidade). Milton nasceu em 1952. Viveu na capital manauara até os quinze anos (1967), onde cursou o Colégio Amazonense D. Pedro II. Em seguida se mudou para Brasília e estudou no Ciem (Centro Integrado de Ensino Médio, colégio de aplicação da unB da época). Em 1970 mudou-se da capital federal (no período brasiliense foi preso em uma passeata contra o regime militar e logo depois solto, fato que resultou num trauma com a ditadura, conforme relata em diversas oportunidades) para São Paulo com o objetivo de estudar arquitetura na USP, onde se formou em 1977.

No final dessa década foi jornalista cultural na revista IstoÉE! por dois anos e professor universitário de História da Arquitetura na Universidade de Taubaté (1978). Em 1979 conseguiu a Bolsa Vitae ${ }^{5}$ para estudar em Madri durante quatro meses, mas permaneceria na Europa por quatro anos (1983). Passou seis meses em Madri e seis meses em Barcelona. Em 1980 ganhou bolsa para estudar na França e realizou pós-graduação em estudos literários na Universidade de Paris III - Sorbonne. Nesse período começou a escrever Relatos de um certo Oriente.

No seu retorno ao Brasil em 1984, encontrou uma Manaus desoladora devido à expansão da Zona Franca e ao crescimento desordenado da cidade. Nesse contexto finalizou seu primeiro livro, em 1987, que seria publicado em 1989 pela editora Companhia das Letras. Ainda em Manaus, foi professor na Universidade Federal do Amazonas (Ufam) - nesse período foi, também, professor-visitante da Universidade da Califórnia, em Berkeley (1996), nos Estados Unidos -, lecionando língua e literatura francesa até o final da década de 1990, quando retornaria a São Paulo (abalado com a morte do pai e o fim do primeiro casamento), já com seu segundo livro Dois irmãos quase pronto (seria editado em 2000). O plano de fazer um doutorado em literatura na USP seria abandonado após a publicação de Dois irmãos.

A hesitação que o impedia de largar a universidade (posição estável) e se dedicar integralmente à literatura (posição instável) acompanhou o processo de escrita de seu segundo livro, que levou aproximadamente dez anos para sair. Essa demora foi interpretada no mundo literário como devoção à arte pura e desinteresse pelo sucesso comercial. Após a publicação de Dois irmãos e a sua acolhida favorável, o ritmo de publicação aumentaria, com intervalo de três ou quatro anos entre cada livro.

Em São Paulo morou nos bairros de Higienópolis e Pinheiros e se casou com a editora Ruth Lanna ${ }^{6}$. Foi colunista do Caderno 2 (O Estado de S. Paulo). Publicou

5. Associação civil sem fins lucrativos que atuou no Brasil entre 1985 e 2005 fomentando Arte e Cultura, através de bolsas de pesquisas e diversas modalidades de financiamento (Cf. Almeida \& Herencia, 2012).

6. Sua atuação no campo editorial se deu principalmente na editora Companhia das Letras e na Planeta. Em 2005 e 2006 foi organizadora da Flip (Festa Literária Internacional de Paraty). 
ainda pela Companhia das Letras: Cinzas do Norte (2005 - romance), Órfãos do Eldorado (2008 - romance), A cidade ilhada (2009 - contos), Um solitário à espreita (2013 - crônicas) e, mais recentemente, dois romances que fazem parte de uma trilogia, respectivamente $A$ noite da espera (2017) e Pontos de fuga (2019). Seus livros foram traduzidos para doze idiomas, em catorze países diferentes. Segundo dados de seu próprio site e de notícias de jornal, teve mais de 315 mil exemplares de todos os seus livros vendidos. Em 2015 lançou uma versão em quadrinhos de Dois irmãos, que recebeu, também, tradução francesa. No Salão do Livro de Paris, no mesmo ano, Milton vendeu mais da sua edição em quadrinhos que Paulo Coelho, segundo o próprio autor ${ }^{7}$. Um dos contos do livro A cidade ilhada, o Relato de um certo Oriente e Órfãos do Eldorado foram adaptados para versões audiovisuais, nos anos seguintes. No ano de 2017, o livro Dois irmãos foi exibido no formato de minissérie na TV Globo.

QUADRO 1

Trajetória Literária de Milton Hatoum

\begin{tabular}{|c|c|}
\hline $\begin{array}{l}\text { CRONOLOGIA DA OBRA DE } \\
\text { MILTON HATOUM }\end{array}$ & EVENTOS \\
\hline 1989 & Publicação de Relatos de um certo Oriente \\
\hline 1990 & Prêmio Jabuti de Melhor Romance para o Relato de um certo Oriente \\
\hline 2000 & Publicação de Dois irmãos \\
\hline 2001 & Prêmio Jabuti ( $3^{\circ}$ lugar) para Dois irmãos \\
\hline 2005 & Publicação de Cinzas do Norte \\
\hline \multirow[b]{2}{*}{2006} & Prêmio APCA e prêmio Portugal Telecom para Cinzas do Norte \\
\hline & $\begin{array}{l}\text { Prêmio Jabuti de Melhor Romance ( } 1^{\circ} \text { lugar), Prêmio livro do ano da Câmara } \\
\text { Brasileira do Livro, Prêmio Bravo! De Literatura }\end{array}$ \\
\hline \multirow[t]{2}{*}{2008} & Publicação de Órfãos do Eldorado \\
\hline & Prêmio Jabuti ( $2^{\circ}$ lugar) para Órfãos do Eldorado \\
\hline 2008 & Ordem do Mérito Cultural do Ministério da Cultura \\
\hline 2009 & Publicação de $A$ cidade ilhada \\
\hline 2013 & Publicação de Um solitário à espreita \\
\hline \multirow[b]{2}{*}{2015} & Lançamento da versão em quadrinhos de Dois irmãos, em português e francês. \\
\hline & $\begin{array}{l}\text { Quatro livros de Milton Hatoum são objeto de adaptações para formatos audiovi- } \\
\text { suais: Dois irmãos (minissérie televisiva), A cidade ilhada, Relato de um certo Oriente } \\
\text { e Órfãos do Eldorado (cinema). }\end{array}$ \\
\hline \multirow[b]{2}{*}{2017} & Minissérie de Dois irmãos é exibida na Tv Globo \\
\hline & $\begin{array}{l}\text { Publicação do primeiro volume da trilogia } O \text { lugar mais sombrio, o livro } A \text { noite } \\
\text { da espera (romance) }\end{array}$ \\
\hline 2019 & Publicação de Pontos de fuga (romance) - segundo volume da trilogia \\
\hline
\end{tabular}

Fonte: Autoria própria com dados da pesquisa.

7. Informação concedida em entrevista ao pesquisador. 
A trajetória de Milton Hatoum se fez possível, de início, a partir de uma socialização nos que eram então os estratos médios / altos de Manaus. A familiarização com línguas estrangeiras desde cedo e o contato com livros e autores clássicos em sua casa (através do incentivo da mãe) ou no Colégio Amazonense D. Pedro II constituíram trunfos culturais necessários à desenvoltura com o mundo literário e com a escrita. Graças a esses aprendizados, o autor viveu boa parte de sua vida à custa de traduções, obteve bolsa de fomento à criação artística e pôde realizar estudos de pós-graduação fora do país. A aposta na educação foi, provavelmente, uma tentativa de compensar o declínio social de sua família ${ }^{8}$.

Vejamos como o autor descreve o processo de aprendizagem do idioma francês:

Do Flaubert há, inclusive, uma história que data da minha juventude, quando aprendi francês em Manaus, nos anos 1960. Eu era muito jovem e minha avó libanesa falava um pouco de francês, de modo que a língua francesa não era desconhecida para mim. $\mathrm{Na}$ minha casa se falava árabe e português, mas quando minha avó nos visitava, ela gostava de praticar a língua francesa. Ela estudara num liceu francófono em Beirute. Aprendi francês com a esposa do cônsul francês em Manaus, quando eu tinha doze ou treze anos. Essa professora me apresentou pela primeira vez os contos do Flaubert, ela lia um trecho de Um coração simples e depois o traduzia. Era uma maneira também de ampliar o vocabulário. (Hatoum apud Gebaly, 2010, p. 5).

Assim, para Hatoum o contato com o francês se deu de forma "natural", dentro de casa com sua mãe, pai e avó e, mais sistematicamente, no Colégio ou em cursos particulares. Teve aulas com falantes de francês provenientes de elites burocráticas de Manaus.

A escolha do curso de arquitetura pode ser entendida como um caminho seguro, no qual afinal não prosseguiria, mas que lhe facilitaria indiretamente o investimento posterior em seus pendores literários. Conforme relatou em entrevista a mim concedida, mesmo no curso de arquitetura, não teria abandonado a paixão pela literatura. Frequentou na USP disciplinas na Letras com os críticos Davi Arrigucci Jr., João Luiz Lafetá e Alfredo Bosi. A partir deles e de suas indicações de leitura teve contato com a literatura hispano-americana que não conhecia (Borges principalmente) e pôde ampliar e adensar seu repertório literário.

8. Como destaca Abreu (2013), a família de Milton Hatoum teve uma trajetória de declínio social, principalmente pelo lado materno. Isso devido ao fato de terem perdido uma casa comercial após a morte do avô e ao casamento descensional celebrado entre a mãe de Milton e o pai, um simples mascate. Segundo a autora, tal situação clássica de descenso estimulou na família uma estratégia de reconversão de capital, ou seja, o filho foi estimulado a acumular capital cultural, como forma de recuperar o capital social e econômico perdido. 
A passagem pela USP foi, desse modo, um passo importante de sua trajetória ao permitir o contato com os críticos literários citados. Indiretamente, a formação como arquiteto tornaria possível o ingresso no universo da cultura, fosse como tradutor, jornalista, professor etc. A obtenção da bolsa da Fundação Vitae, embora considerada pelo autor um grande golpe de sorte, beneficiou um candidato preparado e merecedor de ter sido selecionado.

A bolsa de estudos que permitiu a Hatoum sair do país e se dedicar à escrita de seu primeiro livro foi essencial, assegurando as condições para seu "projeto criador" (Bourdieu, 1968) à distância da ditadura militar brasileira. Tornou possível, também, fazer uma pós-graduação em estudos literários, na cidade de Paris, a Meca dos escritores latino-americanos em todo o século Xx (Casanova, 2002).

Quando o autor retornou ao país em 1984, a ditadura militar estava perto do final. Dotado de mais um título escolar prestigioso e raro, estava habilitado a exercer o posto de professor universitário. Naquele momento as universidades viviam uma expansão de vagas, fruto da política educacional implantada pelos militares, de expansão do sistema universitário (cf. Neves, 2012). Paradoxalmente, como é praxe nas investigações sobre o período militar brasileiro, o mesmo regime que deteve Hatoum, ainda enquanto jovem estudante secundarista, propiciou a ele, anos mais tarde, um posto de trabalho na Universidade Federal do Amazonas (Ufam), episódio que reforça o papel, cada vez mais central nas últimas décadas, desempenhado pela universidade na formação e profissionalização dos produtores literários.

Os anos 1970 e 1980 se caracterizaram fortemente pelo incentivo ao desenvolvimento de uma indústria cultural racionalizada e moderna no país (cf. Ortiz, 1989; Ridenti, 2014). Em seu interior, entretanto, a expansão do mercado editorial nas mesmas décadas não aconteceu sem percalços. $\mathrm{O}$ desgaste do milagre brasileiro e as sucessivas crises econômicas, enfrentadas por intervenções governamentais erráticas, só foram superadas na Nova República com o Plano Real (Hallewell, 2012). Apesar de contar com contingentes populacionais cada vez mais alfabetizados e titulados, a economia do país não garantiu condições para que tais consumidores potenciais comprassem livros de fato (cf. Sá-Earp \& Kornis, 2010). Nesse contexto, o mercado ficou bastante dependente das instáveis compras governamentais, até que, nos anos 1990 e 2000, houvesse ampliação da rede varejista, aumento de renda dos consumidores privados (com o fim da inflação galopante), entre outros fatores, como impulsos persistentes ao mercado editorial, que garantiram grau importante de desenvolvimento tecnológico e profissional no período.

A história da editora Companhia das Letras, fundada em 1986 por Luiz Schwar$\mathrm{cz}$, é emblemática desse processo. Ele provinha da editora Brasiliense, onde iniciou como estagiário e terminou como editor. Segundo Hallewell (2012), a estratégia 
da Companhia se baseava na "coerência da linha editorial", na seleção criteriosa dos títulos, no cuidado na confecção das capas, na apresentação artística e gráfica dos livros, na qualidade das traduções.

Enquanto Hatoum terminava o Relato de um certo Oriente (1987), seu futuro editor dava os primeiros passos com sua editora (1986), escorando-se na venda de alguns livros importantes como Rumo à estação Finlândia de Edmund Wilson, que vendeu cerca de 110 mil exemplares, além de ter firmado parceria de apoio financeiro com a família que controlava o Unibanco (Hallewell, 2012, p. 731). Segundo o próprio Hatoum, Luiz Schwarcz teria chegado até ele por meio das listas de bolsistas da Fundação Vitae. O editor procurava, então, autores que tinham sido contemplados e estavam com obras inéditas por publicar. Era o encontro perfeito para o aspirante a escritor e a editora em construção.

Além dos fatores vinculados ao mercado literário propriamente dito, a vinda posterior de Hatoum para São Paulo deve ser entendida como movimento chave para a construção de sua carreira, já que a capital paulista na virada do século XXI suplantaria o Rio de Janeiro em pujança de produção literária (Cf. Muniz Jr., 2016), não obstante esta última ainda fosse e seja um centro literário importante do país?. Em outras palavras, tal migração, como tantos deslocamentos geográficos recorrentes na história de sua família, foi crucial para sua afirmação no espaço literário.

Também o conjunto de produtores literários que atuavam no tempo de Hatoum e o cânone com que o autor dialoga/dialogou são dimensões importantes para se entender como ele teria construído seu "projeto criador" (Bourdieu, 1968). Nos trabalhos sobre Milton Hatoum são mencionados os escritores conhecidos ou não que o influenciaram. Segundo Hallewell (2012), antes da estreia do autor, a literatura manauara havia prosperado, favorecida pelo impulso dado no início da ditadura militar pelo governador Arthur Cezar Ferreira Reis (gestão entre 1964 e 1967), que promoveu através da máquina de seu estado um conjunto de publicações sobre história, sociologia e literatura amazonense.

Pouco depois despontaria Márcio Souza, funcionário municipal de Manaus, ao lançar em 1976 o romance intitulado Galvez, Imperador do Acre. Entretanto, devido ao conteúdo da obra ser considerado ultrajante em relação à história local, ele foi demitido de seu cargo. Após a exoneração, foi para São Paulo e, em seguida, fundou a editora Marco Zero e fez de seu livro um best-seller com 150 mil exemplares

9. Diferentemente de campos literários nacionais fortemente centralizados em uma única cidade, como são o argentino (Buenos Aires) e o mexicano (Cidade do México), na América Latina, e o francês e o inglês, na Europa, o campo brasileiro sempre foi relativamente descentralizado - como o alemão, o italiano e o estadunidense -, e disputado entre São Paulo e o Rio de Janeiro desde o século xx. 
vendidos. Seu romance seguinte, Mad Maria (1980), obteve grande repercussão, inclusive no exterior, e foi adaptado como uma minissérie televisiva (2005) veiculada pela TV Globo com sucesso ${ }^{10}$.

Um dos nomes constantemente mencionados como antecessor de Hatoum é o de Raduan Nassar. Autor intensamente celebrado pela crítica, entretanto, Raduan sempre foi muito avesso a qualquer estratégia pessoal de legitimação. De qualquer forma, após sua consagração, ao lado de Dalton Trevisan e Rubem Fonseca, como representantes autênticos da grande tradição, cujos últimos nomes haviam sido Clarice Lispector, João Guimarães Rosa e João Cabral de Melo Neto ${ }^{11}$, demoraram a surgir novos escritores à altura, mas sugiro que Milton Hatoum disputou esse reconhecimento, entre os autores mais destacados da literatura brasileira atual ${ }^{12}$. Aparentemente, o próprio autor ansiou essa consagração e a perseguiu, levando em conta o "espaço dos possíveis” com o qual se deparou (Wells, 2007).

Em estudo que discute a recepção dos livros de Hatoum, Maria Cristo (2007) enfatiza, como linha característica desse autor, "o trabalho com a escrita, o manuseio cuidadoso da palavra” (Cristo, 2007, p. 11). Esse zelo com a palavra é comparado ao cuidado dos arquitetos com as edificações (dado que a formação inicial de Hatoum é a de arquiteto).

A trajetória de Hatoum se cruza, direta ou indiretamente, às de vários escritores, como Márcio Souza, Paulo Coelho e Raduan Nassar. O primeiro, Márcio Gonçalves Bentes de Souza, nasceu em Manaus em 1946. Era filho de linotipista, estando desde cedo próximo de livros. Passou a infância e adolescência em Manaus, onde concluiu o curso científico. Posteriormente seguiu para São Paulo, em 1963, onde cursou Ciências Sociais entre 1966 e 1969, sem, contudo, concluir a graduação. No retorno a Manaus atuou como dramaturgo e cineasta, fez parte do Teatro Experimental do

10. A minissérie foi adaptada por Benedito Ruy Barbosa e dirigida por Ricardo Waddington, protagonizada por Ana Paula Arósio e Fábio Assunção

11. Três panoramas sobre a produção literária que abordam os anos 1980 são interessantes. Dois textos de Antonio Candido $(1981,2010)$ tentam dar conta do que teria aparecido de novo após Clarice Lispector, Guimarães Rosa e João Cabral de Melo Neto. E o texto de Süssekind (1985) dá um tratamento eloquente ao sentimento de que não havia surgido ainda alguém que tivesse superado a prosa e escrita de Raduan Nassar.

12. Podemos mencionar como outros candidatos a essa posição de prestígio, embora um pouco mais jovens, o carioca Bernardo Carvalho (1960) e o paulista Nuno Ramos (1960). Ambos são mais avessos ao sucesso comercial, talvez por disporem de outros meios de vida como o jornalismo e as artes plásticas, respectivamente. 
Sesc/Amazonas (Tesc), escrevendo diversas peças teatrais. O período como teatrólogo durou aproximadamente doze anos. Devido ao forte tom crítico de diversas de suas peças, em 1981 o Tesc teve suas atividades encerradas, e o autor se mudou em definitivo para o Rio de Janeiro em 1983. Em 1976, conforme mencionado, publicou o romance-folhetim Galvez, Imperador do Acre. Desde este livro, o autor passou a publicar em média quase um por ano, entre os quais se destacam: Operação silêncio (1979) e Mad Maria (1980). Nos anos 1990, Márcio Souza teve participação em dois órgãos estatais ligados à cultura: foi diretor do Departamento Nacional do Livro (da Fundação Biblioteca Nacional) e depois, entre 1995 e 2002, presidente da Funarte (Fundação Nacional da Arte). Segundo registra Carvalho (2005), foi um dos poucos autores do período a viver somente de seus direitos autorais.

Como se depreende da trajetória de Márcio Souza, o autor esteve em muitos momentos de sua carreira ligado a temáticas políticas, utilizando a literatura e a dramaturgia como formas de intervenção na esfera pública. Também teve atuação na política institucional assumindo cargos ligados ao universo da cultura. Se Márcio Souza representa de certa maneira uma face mais engajada e política de escritor, por outro lado Paulo Coelho é reconhecido pelo sucesso comercial obtido com seus livros.

Paulo Coelho havia sido diretor da companhia de discos СвS e secretário de redação do jornal $O$ Globo. Antes da publicação de $O$ diário de um mago em 1987, já tinha publicado outros livros de menor repercussão, sobre teatro, vampirismo etc. $O$ diário de um mago foi publicado pela Editora ECO, cujo editor, Emanuele Mandarino, investia então em livros de "linha esotérica", pressentindo espaço para esse gênero no mercado literário de então.

O alquimista (1988) é o livro brasileiro mais vendido de todos os tempos. Sua obra foi editada em mais de 150 países e traduzida em 69 línguas. Desconsiderado pela crítica literária e pelos escritores do polo erudito, é somente trazido à baila como exemplo de má qualidade literária e de rebaixamento da arte aos valores comerciais e econômicos imediatos. Estando assim fora do polo erudito e de circulação restrita, ele seria o "rei do outro polo", o de circulação ampla e comercial (cf. Pinheiro Filho, 2014). Nessa posição, granjeou o ingresso na Academia Brasileira de Letras, ocupando a cadeira n. 21, em 2002.

Não interessa neste artigo entrar nos meandros das trajetórias desses dois autores, mas sinalizar as posições distintas que representam no campo literário: de um lado, uma literatura de grande circulação ligada ao mercado (Paulo Coelho); de outro lado, uma literatura engajada politicamente (Márcio Souza), porém mais próxima do polo erudito. Souza é considerado interlocutor legítimo por Hatoum, tendo alcançado, também, certo sucesso comercial (Carvalho, 2005). 
Entre essas alternativas, Hatoum teria optado por uma terceira, com a ambição de se inscrever no eixo da literatura erudita. O escritor mais próximo no tempo e no espaço, de quem Hatoum se reivindica sucessor, como vimos, é Raduan Nassar. Sarah Wells (2007) escolhe um título bastante esclarecedor, O improvável sucessor de Nassar: a genealogia alternativa de Milton Hatoum, para discutir as linhas de continuidade e sucessão na literatura brasileira. Esse artigo foi publicado no livro coletivo sobre Milton Hatoum, organizado por Maria Cristo (2007). Vale citar:

Como argumenta astutamente José Castello, a posição ambígua e altamente cética de Nassar com respeito aos locais onde é produzida a crítica brasileira certamente deixou sua marca; Hatoum, por outro lado, articulou uma posição menos maldita como autor público, tanto dentro quanto fora do Brasil. Como, então, entender o paralelo entre os dois escritores e, em particular, o modo como Hatoum declarou Nassar seu antecessor literário? (Wells, 2007, p. 61).

Apesar das diferenças entre Nassar e Hatoum, identificadas pela autora, sobretudo em relação ao papel mais ativo de Hatoum como autor público, haveria também, entre eles, elementos de aproximação. Raduan Nassar nasceu em 1935 na cidade de Pindorama, no interior do Estado de São Paulo, filho de um casal de libaneses (ascendência semelhante à de Hatoum). Realizou seus primeiros estudos na cidade natal e depois o secundário em Catanduva (SP), onde morou de 1949 até 1953, quando migrou para São Paulo. Já na capital estudou no Instituto de Educação Fernão Dias, no bairro de Pinheiros, onde a família morava e possuía um armarinho chamado Bazar 13 (filho e pai trabalhavam juntos no comércio durante o dia). Em 1954, Nassar concluiu o científico. A seguir entrou na Faculdade de Direito do Largo São Francisco (USP) e na Faculdade de Filosofia, Ciências e Letras da mesma universidade. Não concluiria o curso de direito, mas sim o de filosofia, em 1963. Ainda na universidade realizou uma viagem aos Estados Unidos e Canadá, afastando-se do trabalho no armarinho chefiado pela família na zona oeste de São Paulo.

Viajou posteriormente, também, para a Alemanha Ocidental, passando pelo Líbano para visitar a aldeia de origem de seus pais. De volta ao Brasil, com um breve interregno como criador de coelhos em um sítio em Cotia (1963-1965), fundou um jornal com um irmão e começou uma leitura do Alcorão, em 1968, que embasou seu primeiro romance, Lavoura arcaica (1975). O livro foi publicado pela editora José Olympio, que contou com apoio financeiro do autor para a publicação.

Seu segundo título, a novela Um copo de cólera, foi lançado em 1978. Em 1984, adquiriu uma fazenda em Buri, São Paulo, e passou a se dedicar à atividade rural se afastando da vida literária, apesar do lançamento muito posterior de uma coletânea de contos chamada Menina a caminho, em 1997. 
Logo pelo primeiro livro, o autor recebeu prêmios importantes: a premiação da Academia Brasileira de Letras, o Prêmio Jabuti e o APCA (da Associação Paulista dos Críticos de Arte de São Paulo). Seus livros foram traduzidos rapidamente para o espanhol (Alfaguara), para o francês (Gallimard), e no Brasil o autor foi editado posteriormente pela Nova Fronteira, Brasiliense e, ao final, Companhia das Letras. Apesar de ter sido sempre muito reservado, nos últimos tempos tem aparecido nos noticiários literários e políticos, após ganhar o Prêmio Camões (2016) e manifestar-se sobre questões candentes da política nacional. Nassar é considerado o principal romancista brasileiro das décadas de 1970 e 1980 e é recorrente a associação de seu nome ao de Milton Hatoum ${ }^{13}$.

A legitimação de Hatoum como sucessor de Raduan Nassar dificilmente ocorreria, entretanto, sem a Companhia das Letras, que o inseriu no mundo literário de maneira prestigiosa, consagração que serviria à editora como prova de sua excelência.

A Companhia das Letras, ao surgir em 1986, trouxe como novidade um projeto editorial que dizia pretender conciliar profissionalismo e a relevância cultural e literária das obras a serem publicadas, ou seja, autodefinia-se pela união das dimensões empresarial e cultural: a Companhia e as Letras. A atividade da Companhia das Letras marcou o campo editorial brasileiro na virada do século XX para o XXI, tornando-se uma indicação de qualidade para os livros editados e uma possibilidade de consagração literária e lucros financeiros para os seus autores. Acabou se tornando referência para o sistema editorial brasileiro pela qualidade técnica e pelo valor cultural atribuído a seus livros, e não pela quantidade de livros produzidos ou pelo lucro auferido. (Koracakis, 2010, p. 289).

Reconhecida por suas concepções editoriais e profissionais, a editora aberta por Luiz Schwarcz carrega essa marca de reunir sucesso comercial, qualidade literária e importância cultural e acadêmica. Cada vez mais, tornou-se fiadora do prestígio dos seus autores.

A Companhia sempre foi muito atenta à divulgação de seus lançamentos na imprensa ${ }^{14}$. Recentemente, projetou-se ainda mais como uma das patrocinadoras

13. Em obra organizada pelo Instituto Moreira Salles (2001) em homenagem a Raduan Nassar, podemos localizar um depoimento de Milton Hatoum a respeito da influência que Nassar possui em sua obra. Entre elogios e deferências, Hatoum descreve até um encontro com Nassar, na fazenda deste, no qual Hatoum conversa com o colega sobre seus manuscritos, pedindo conselhos ao seu mestre.

14. "Com a abertura política dos anos 1980 e o crescimento da indústria cultural, as editoras passaram por uma grande profissionalização - e a Companhia das Letras, surgida em 1986, tornou-se símbolo dessa época, pois conseguiu sucesso comercial com a produção de livros de qualidade, sobretudo em se tratando de tradução e produção gráfica, mas sem uma ligação direta com os grandes debates políticos e sociais do país. Para garantir esse sucesso aumentou o lobby dos editores na pauta dos jornais, em que 
principais da Festa Literária Internacional de Paraty (Flip), iniciada em 2003 (cf. Moura, 2005) ${ }^{15}$. Sua fusão com a Penguin Random House ${ }^{16}$ confirmou sua liderança no campo editorial brasileiro e seu prestígio internacional, sem comprometer sua orientação anterior, de editar livros de qualidade com sucesso de vendas.

A socióloga Gisèle Sapiro (2014) diferencia duas estratégias típicas de escritores de escrita e de autor: a primeira se liga às intenções envolvidas na escrita (rompimento ou adesão a certas formas textuais, escolhas temáticas, composição de personagens etc.); a segunda ao acúmulo do capital simbólico visando à consagração literária.

Processos como diversificação das mídias, profissionalização e especialização na comercialização editorial aumentaram a necessidade de construção de uma imagem do autor, cada vez mais solicitado a apresentar-se publicamente em eventos diversos de divulgação e debates literários. Em tais ocasiões é importante que o autor mesmo fale, como o criador do texto e seu defensor ${ }^{17}$. A combinação dessas três instâncias é reputada como signo de autoridade intelectual (Goffman, 1981).

As leituras públicas são frequentemente acompanhadas de mudanças de entonação, pausas e acelerações de ritmo, que introduzem uma imagem do escritor que não aparece no texto impresso, explicitando sua "estratégia de autor". Além disso, a leitura permite apenas uma relação de via única com o autor, enquanto a presença em uma conferência torna possível uma relação direta entre público e escritor (Goffman, 1981) ${ }^{18}$.

ocorre uma rede de sociabilidade que ajuda a determinar as escolhas dos livros que serão resenhados no jornal e de quais intelectuais comentarão estes textos." (Lima, 2013, pp. 106/107).

15. O lobby intenso em jornais para que fossem pautados livros da editora se combinou com a atuação decidida e direta de Luiz Schwarcz na criação e concepção de novas instâncias de consagração e legitimação literária no Brasil, como a Flip, evento de que o editor teve papel decisivo de mentor (Koracakis, 2010).

16. "A empresa que começou com capital levantado por Luiz Schwarcz pela venda de um de seus apartamentos e dinheiro emprestado pela família dona da gráfica Cromocart. Já em 1988 tem uma parcela das ações compradas pela empresa Caminho Editorial, do Grupo Moreira Salles, proprietário à época do Unibanco. Eles adquiriram 33\% de participação nas ações da empresa, sendo o restante de Schwarcz. O Grupo passou a ser representado à época no conselho editorial através da figura de Fernando Moreira Salles. Depois, mais adiante viriam a venda de participação acionária à Penguin e depois a fusão desta com a Random House, forçando uma mudança e a criação do Grupo Companhia das Letras, que passa a controlar a editora Objetiva e alguns outros selos de interesse geral do grupo Santillana." (Stella, 2018, p. 114).

17. Goffman, centrado mais nas interações face a face e em suas dinâmicas, propõe analiticamente uma cisão entre um eu textual e um eu performer (orador) no ato de um falante proferir uma conferência: a este eu textual, corresponderiam as estratégias de escrita, de que fala Sapiro (2014); e ao eu performer, as estratégias de autor.

18. Em sua análise sobre Clarice Lispector, Fernando Pinheiro (2019) sugere que Goffman ultrapassa o problema da mimese literária, ao entender a literatura como jogo social, envolvido na construção da realidade. Fernando Pinheiro relaciona, ainda, as estratégias de escrita ao eu textual, e às estratégias 
Milton Hatoum adota como estratégia de escrita a identificação com o polo autônomo (de circulação restrita) da literatura. Em seus textos sobressaem o manejo da tradição literária brasileira, as citações indiretas de autores clássicos por meio da construção de personagens e a adoção de técnicas vinculadas à estrutura do romance contemporâneo - representação consciente pluripessoal, estratificação temporal, relaxamento da conexão com acontecimentos externos, mudança da posição da qual se relata (Auerbach, 2015). Tais elementos são encontrados, sobretudo, em seu primeiro livro, Relato de um certo Oriente (2008).

Se sua estratégia de escrita reivindica a inscrição no polo autônomo de produção, sua estratégia de autor é mais flexível e atenta à lógica econômica de sua profissão. Nessa direção, o autor escreve na grande imprensa, comparece a diversos eventos (feiras, bienais, festas de livro, conferências acadêmicas), adapta obras para o suporte audiovisual (curtas-metragens e longas-metragens, minisséries etc.) e outros formatos (quadrinhos). Ele mesmo parece dar-se conta, reflexivamente, dessa atitude ambivalente, talvez a mais ajustada ao estado contemporâneo do campo:

Este é o lugar social da literatura: uma maneira enviesada ou indireta de conhecimento do mundo, de nós mesmos e do Outro. Essa ausência de utilidade prática vai contra o mercado, mas o fato de você publicar um livro significa estar sujeito a algum tipo de consumo. Escrever com os olhos só no mercado e no sucesso imediato não me parece o melhor caminho para quem quer ser romancista. Por outro lado, o fracasso não é garantia de nada, como disse Jorge Luis Borges. (Hatoum apud Barreto \& Mello, 2007, p. 30, grifo meu).

Tal afirmação indica as dificuldades encontradas pelo autor de transitar unicamente no polo de circulação restrita da literatura. Aliás, tal polo não se construiu totalmente desvinculado do polo comercial no Brasil (cf. Ortiz, 1989; Ridenti, 2014); e, mesmo em campos literários poderosos como o da França, o final do século $\mathrm{xx}$ foi marcado pelo recrudescimento das lógicas econômicas da atividade literária (Bourdieu, 1999).

Nesse sentido, a fala de Hatoum pode ser compreendida se vinculada ao projeto da Companhia das Letras de publicar livros de qualidade e bem-sucedidos comercialmente, os "clássicos contemporâneos" ou "best-sellers de qualidade”. Cada vez mais, com o crescimento dos grandes grupos editoriais, essa exigência se torna premente, constrangendo escritores e escritoras a atentarem às lógicas literária e econômica

de autor ao eu performático (orador, locutor), correspondendo este último às formas como o escritor representa a si nas relações face a face ou em outras diversas ocasiões de mostrar-se a si mesmo no espaço literário. 


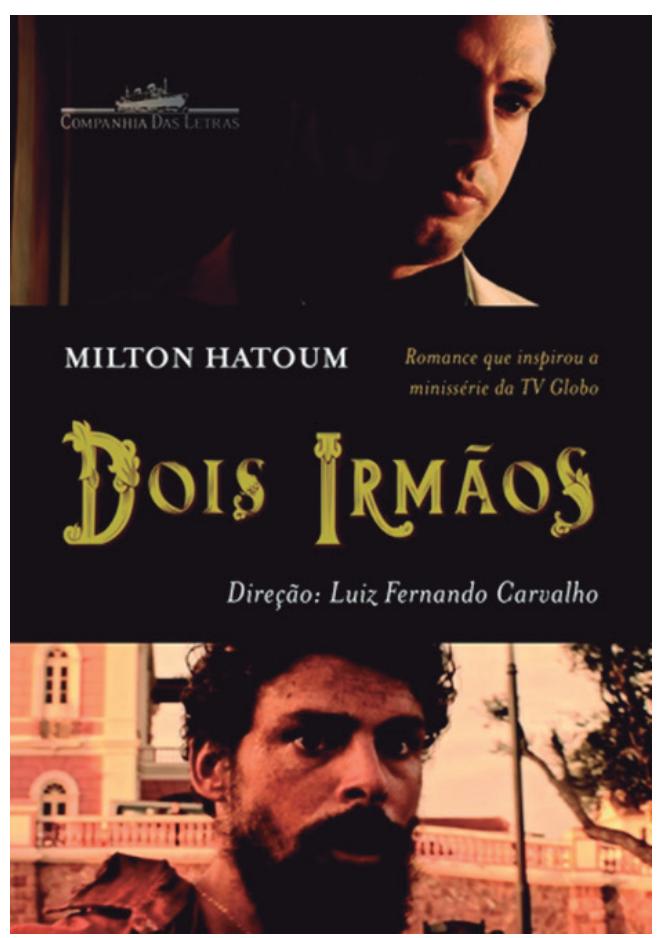

Imagem 1 - Sobrecapa da edição de bolso de Dois irmãos (Foto do autor).

de sua atividade, sem o que em geral se torna inviável a carreira. Vejamos por meio de Dois irmãos como a diversificação dos formatos e a publicidade foram decisivas à sua recepção ampliada.

A primeira tiragem de Dois irmãos (2000) foi de 3 mil exemplares; em 2001, segundo Piza (2007), a vendagem chegou a 30 mil exemplares. Recentemente, com a realização de uma minissérie na TV Globo ${ }^{19}$ que adaptou o livro e foi veiculada em janeiro de 2017, em um mês o livro alcançou em vendas praticamente o número de sua primeira tiragem (cf. Neto, 2016) ${ }^{20}$.

Além do aumento da vendagem, o número de telespectadores foi superlativo. Segundo dados do Ibope, que realiza a medição da audiência televisiva, teriam

19. A minissérie Dois irmãos, de 2017, teve direção geral de Luiz Fernando Carvalho, mesmo diretor do filme Lavoura arcaica (2001), baseado no livro de mesmo título de Raduan Nassar.

20. Os números de vendas, em dezembro de 2018, dos três primeiros livros de Milton Hatoum são, de acordo com a Companhia das Letras: Dois irmãos vendeu de seu lançamento até hoje aproximadamente 190 mil exemplares (75 mil na edição tradicional e 115 mil em livros de bolso), Relato de um certo Oriente vendeu aproximadamente 53 mil exemplares (28 mil na edição tradicional e mais 25 mil em livros de bolso), e Cinzas do Norte vendeu aproximadamente 60 mil exemplares no total (50 mil exemplares na edição tradicional e 10 mil em livros de bolso). 
assistido à estreia da minissérie aproximadamente 4.253.001, somente na região da Grande São Paulo (cf. Forato, 2016; Junior, 2017).

Tal público foi alcançado raríssimas vezes por autores brasileiros somente pelo suporte livro, talvez apenas por Paulo Coelho e Jorge Amado. O exemplo demonstra a força que a televisão adquiriu no Brasil e o efeito que ela exerce sobre o campo literário, corroborando a interpretação de Reimão (1996, 2001, 2011). A respeito, a sobrecapa da edição de bolso é expressiva.

Muitas das decisões acima mencionadas não são de responsabilidade exclusiva do autor do livro, cabendo boa parte delas à sua editora. Porém, todas contam com sua anuência, já que aceitou negociar e vender os direitos de adaptação e exploração comercial de sua obra.

$\mathrm{O}$ equilíbrio bem-sucedido entre as duas estratégias de Hatoum tem a ver com o acúmulo de capital simbólico em diversas instâncias de consagração ao longo da carreira: premiações, crítica literária, universidade, jornalismo, meio editorial, instituições privadas de cultura etc. A desenvoltura em circular por meios diferentes o habilitou a assumir um papel central no campo literário contemporâneo, com o suporte decisivo de sua editora, a Companhia das Letras, que reivindicou Milton Hatoum como o escritor mais destacado de sua geração, como um clássico contemporâneo. Em contrapartida, a consagração do escritor representou, também, a consagração da editora. Houve entre ambos um casamento perfeito, muito revelador para se compreenderem as lógicas que presidem o campo literário contemporâneo, no qual os escritores mais reconhecidos por seus pares não podem evitar as constrições econômicas que pesam sobre sua atividade. As estratégias de longo prazo (arte pura) devem ser conjugadas às de curto prazo (arte comercial).

Essa sintonia difícil implica uma tensão inevitável entre a busca pela autonomia criativa e o sucesso comercial.

Referências Bibliográficas

Abreu, Jane Gabriele de Sousa. (2013), O caminho das letras: um estudo das trajetórias de Milton Hatoum e Chico Buarque. São Paulo, dissertação de mestrado, Programa de Pós-Graduação em Engenharia Civil - pPGEC da Universidade de São Paulo.

Almeida, Gabriela Sandes Borges de \& Herencia, José Luiz. (2012), "A Fundação Vitae e seu legado para a cultura brasileira - Parte I: Fontes conceituais, linhas diretivas, programas próprios e legados". III Seminário Interno Políticas Culturais. Disponível em http://culturadigital.br/politicaculturalcasaderuibarbosa/files/2012/09/Gabriela-Sandes-Borges-de-Almeida-et-alii.pdf, consultado em 05/03/2018. 
Auerbach, Erich. (2015), Mimesis: a representação da realidade na literatura ocidental. São Paulo, Perspectiva.

Bourdieu, Pierre. (1968), “Campo intelectual e projeto criador”. In: Pouillon, J. et al. (orgs.). Problemas do estruturalismo. Rio de Janeiro, Zahar, pp. 105-45.

Bourdieu, Pierre. (1996), As regras da arte: gênese e estrutura do campo literário. São Paulo, Companhia das Letras.

Bourdieu, Pierre. (1999), "Une révolution conservatrice dans l'édition". Actes de La Recherche en Sciences Sociales. Paris, 1 (126): 3-28. Persee Program. http://dx.doi.org/10.3406/ arss.1999.3278.

Bourdieu, Pierre. (2001), "O costureiro e sua grife: contribuição para uma teoria da magia”. Educação em Revista, 34: 7-66.

Barreto, Ricardo Gonçalves \& Mello, Jefferson Agostini. (2007), “Entrevista com Milton Hatoum”. In: CRISTO, Maria da Luz Pinheiro de (org.). Arquitetura da memória: ensaios sobre os romances Dois irmãos, Relato de um certo Oriente $e$ Cinzas do Norte de Milton Hatoum. Manaus, Editora da Universidade Federal do Amazonas/Uninorte, pp. 23-33. Originalmente publicada pela Revista Magma - UsP.

CANdido, Antonio. (dez. 1981), “Os brasileiros e a literatura latino-americana”. Novos Estudos Cebrap, São Paulo, 1 (1): 58-68. Disponível em http://novosestudos.uol.com.br/produto/ edicao-01/\#58d20aedeecfa, consultado em 24/08/2017.

CANdido, Antonio. (2010), Iniciação à literatura brasileira. 6 ed. Rio de Janeiro, Ouro sobre Azul.

Casanova, Pascale. (2002), A república mundial das letras. São Paulo, Estação Liberdade.

Carvalho, João Carlos de. (2005), Amazônia revisitada: de Carvajal a Márcio Souza. Rio Branco, Edufac.

Cristo, Maria da Luz Pinheiro de. (2007), “Introdução”. In: Cristo, Maria da Luz Pinheiro de (org.). Arquitetura da memória: ensaios sobre os romances Dois Irmãos, Relato de um certo Oriente $e$ Cinzas do Norte de Milton Hatoum. Manaus, Editora da Universidade Federal do Amazonas/Uninorte, pp. 9-11.

Forato, Thiago. (7 jan. 2016), "Ibope atualiza representatividade de 1 ponto de audiência”. Uol/na Telinha. São Paulo, pp. 1-2. Disponível em http://natelinha.uol.com.br/ noticias/2016/01/07/ibope-atualiza-representatividade-de-1-ponto-de-audiencia-veja-comparativo-95454.php, consultado em 03/05/2017.

Gebaly, Maged T. M. A. El. (maio 2010), "Milton Hatoum: 'Não há tantos tradutores de literaturas de língua portuguesa”'. Revista Crioula, São Paulo, 7: 1-19. Disponível em http:// www.revistas.usp.br/crioula/article/view/55258/58887, consultado em 14/7/2016.

Goffman, Erving. (1981), “The lecture”. In: Goffman, Erving. Forms of talk. Philadelphia, University of Pennsylvania Press, pp.160-196.

Hallewell, Laurence. (2012), O livro no Brasil: sua história. Tradução de Maria da Penha Villalobos, Lólio Lourenço de Oliveira e Geraldo Gerson de Souza. São Paulo, Edusp. 
Hatoum, Milton. (2006), Dois irmãos. São Paulo, Companhia das Letras.

Hatoum, Milton. (2008), Relato de um certo Oriente. São Paulo, Companhia das Letras.

Instituto Moreira Salles (São Paulo). (2001), Raduan Nassar, Cadernos de Literatura Brasileira. 2 ed. São Paulo, IMs, 95 p.

Junior, Aloizio. (11 jan. 2017), "Saiba a audiência de estreia da minissérie Dois Irmãos em cidades do Nordeste”. IG/TVfoco. São Paulo, pp. 1-2. Disponível em http://www.otvfoco. com.br/saiba-a-audiencia-de-estreia-da-minisserie-dois-irmaos-em-cidades-do-nordeste/, consultado em: 03/05/2017.

Koracakis, Teodoro. (2010), “Uma história em processo: a Companhia das Letras de 1986 a 2006”. In: BragançA, Aníbal \& Abreu, Márcia (orgs.). Impresso no Brasil: Dois séculos de livros brasileiros. São Paulo, Editora Unesp, capítulo 16, pp. 289-302.

Lima, Marcelo. (2013), Jornalismo cultural e crítica: a literatura brasileira no suplemento Mais. Curitiba: Editora UfPR; Argos.

“MÁrcio Souza”. (2017), In: ENCICLOPÉDIA Itaú Cultural de Arte e Cultura Brasileiras. São Paulo, Itaú Cultural. Disponível em http://enciclopedia.itaucultural.org.br/pessoa5552/ marcio-souza, consultado em 28/04/2017. Verbete da Enciclopédia.

Mascagna, Selma R. (2015), Rastros de uma origem: espaço, tempo e subjetividade na obra Dois irmãos de Milton Hatoum. São Paulo, dissertação de mestrado em Literatura Brasileira, Faculdade de Filosofia, Letras e Ciências Humanas da Universidade de São Paulo. Dor: 10.11606/D.8.2015.tde-17092015-163146, consultado em 23/05/2017.

Moura, Flávio Rosa de. (2004), Diálogo crítico: disputas no campo literário brasileiro (19842004). São Paulo, dissertação de mestrado em Sociologia, Faculdade de Filosofia, Letras e Ciências Humanas da Universidade de São Paulo.

Moura, Flávio Rosa de. (10 nov. 2005), “A fetichização do conhecimento”. Revista Trópico. São Paulo, pp. 1-2. Disponível em http://www.revistatropico.com.br/tropico/html/ textos/2681,1.shl, consultado em 03/05/2017.

Moura, Flávio Rosa de (org.). (2012), Paraty éuma festa: dez anos de Flip. São Paulo/ Brasília, Associação Casa Azul/Ministério da Cultura.

Muniz Jr., José de Souza. (2016), Girafas e bonsais: editores “independentes” na Argentina e no Brasil (1991-2015). São Paulo, tese de doutorado em Sociologia, Faculdade de Filosofia, Letras e Ciências Humanas da Universidade de São Paulo.

Neto, Leonardo. (12 jan. 2016), “Efeito Globo”. Publishnews. São Paulo, pp. 1-1. Disponível em http://www.publishnews.com.br/materias/2017/01/12/efeito-globo, consultado em 03/05/2017.

Neves, Clarissa. (2012), “Ensino superior no Brasil: expansão, diversificação e inclusão”. In: International Congress of The Latin American Studies Association, 30. Trabalho Apresentado. São Francisco, Lasa, pp. 1-18. Disponível em http://www.ufrgs.br/geu/Artigos 2012/ Clarissa Baeta Neves.pdf, consultado em 02/06/2017. 
Ortiz, Renato. (1989), A moderna tradição brasileira. 2 ed. São Paulo, Brasiliense.

Pinheiro Filho, Fernando. (2014), “O rei do outro Polo”. In: Miceli, Sérgio \& Pontes, Heloisa (orgs.). Cultura e sociedade: Brasil e Argentina. São Paulo, Edusp, pp. 241-268.

Pinheiro Filho, Fernando. (2019), O mago, o santo e a esfinge: três experimentos em sociologia da literatura. São Paulo, tese de livre-docência em Sociologia, Faculdade de Filosofia, Letras e Ciências Humanas da Universidade de São Paulo.

Pouly, Marie-Pierre. (dez. 2016), "Playing both sides of the field: The anatomy of a 'quality' bestseller". Poetics. [s.l.], (59): 20-34. Elsevier Bv. http://dx.doi.org/10.1016/j.poetic.2016.02.002.

"Raduan Nassar". (2017), In: EnciClopédia Itaú Cultural de Arte e Cultura Brasileiras. São Paulo: Itaú Cultural, 2017. Disponível em http://enciclopedia.itaucultural.org.br/ pessoa255670/raduan-nassar, consultado em 28/04/2017. Verbete da Enciclopédia. ISBN: 978-85-7979-060-7.

Reimão, Sandra. (1996), Mercado editorial brasileiro: 1960-1990. São Paulo, Com-Arte/Fapesp. Reımão, Sandra. (2001), “Os best-sellers de ficção no Brasil, 1990/2000”. In: XXIV Congresso Brasileiro de Com./ Intercom, Campo Grande. Anais... Campo Grande, Intercom. Disponível em http://www.portcom.intercom.org.br/pdfs/1035042239758408352963138736 4826498482.pdf, consultado em 29/05/2016.

Reimão, Sandra. (jul./dez. 2011), "Tendências do mercado de livros no Brasil: um panorama e os best-sellers de ficção nacional (2000-2009)”. Matrizes. São Paulo, ano 5, 1: 194-210. Disponível em http://www.matrizes.usp.br/index.php/matrizes/article/view/207, consultado em 29/05/2016.

Ridenti, Marcelo. (2014), “Caleidoscópio da cultura brasileira”. In: Miceli, Sérgio \& PonTES, Heloisa (orgs.). Cultura e sociedade: Brasil e Argentina. São Paulo, Edusp, pp. 21-72.

SÁ-EArp, Fabio \& Kornis, George. (2010), “Em queda livre? A economia do livro no Brasil (1995-2006)”. In: Bragança, Aníbal \& Abreu, Márcia. Impresso no Brasil: Dois séculos de livros brasileiros. São Paulo, Editora Unesp, Cap. 20. pp. 349-362.

SAPIro, Gisèle. (2014), La sociologie de la litterature. Paris, La Découverte.

SAPIro, Gisèle. (12 jul. 2019), A noção de campo de uma perspectiva transnacional. Plural Revista de Ciências Sociais, 26 (1): 233-265.

Stella, Marcello Giovanni Pocai. (2018), Literatura como vocação: escritores brasileiros contemporâneos no pós-redemocratização. São Paulo, dissertação de mestrado em Sociologia, Faculdade de Filosofia, Letras e Ciências Humanas da Universidade de São Paulo. Dor: 10.11606/D.8.2019.tde-29032019-134526, consultado em 01/06/2019.

SüSSEKIND, Flora. (1985), Literatura e vida literária: polêmica, diários \& retratos. Rio de Janeiro, Ed. Jorge Zahar.

Wells, Sarah. (2007), “O improvável sucessor de Nassar: a genealogia alternativa de Milton Hatoum”. In: CRIsto, Maria da Luz Pinheiro de (org.). Arquitetura da memória: ensaios 
sobre os romances Dois Irmãos, Relato de um certo Oriente $e$ Cinzas do Norte de Milton Hatoum. Manaus, Editora da Universidade Federal do Amazonas/Uninorte, 2007, pp. 60-78.

\section{Resumo}

Milton Hatoum: um clássico contemporâneo

Nas capas dos livros de Milton Hatoum editados pela editora Companhia das Letras, é possível vez ou outra deparar com um pequeno adesivo redondo de cor amarela e letras de cor preta, em que se lê: "Um clássico da literatura brasileira contemporânea". O presente artigo procura cercar a construção do escritor Milton Hatoum e de sua obra como clássico brasileiro contemporâneo. Tal empreendimento se baseia principalmente nos preceitos metodológicos estabelecidos por Pierre Bourdieu de investigação de campos artísticos: suas gêneses e processos de autonomização. Investiga-se aqui a posição social do escritor e de sua trajetória no interior do campo literário brasileiro contemporâneo e também do espaço social mais amplo.

Palavras-chaves: Sociologia da literatura; Literatura brasileira; Milton Hatoum; Clássico contemporâneo; Sociologia da cultura.

\section{Abstract}

Milton Hatoum: contemporary classic

In the covers of Milton Hatoum's books published by Companhia das Letras, it is possible to see a small round yellow sticker inside in black letters one reads "A contemporary classic of Brazilian literature". This article seeks to surround the construction of the writer Milton Hatoum and his work as a contemporary Brazilian classic. This enterprise is based mainly on the methodological precepts established by Pierre Bourdieu of investigation of artistic fields: it's genesis and processes of autonomization. We investigate the social position of the writer and his trajectory within the contemporary Brazilian literary field as well as the wider social space.

Keywords: Sociology of literature ; Brazilian literature ; Milton Hatoum; Contemporary classic; Sociology of culture.

Texto recebido em 19/7/2019 e aprovado em 16/9/2020.

DOI: 10.11606/0103-2070.ts.2021.160095.

Marcello Giovanni Pocai Stella é doutorando em Sociologia na Universidade de São Paulo, PPGS-USP. Tem como grande área de estudo a sociologia da literatura e a sociologia da cultura. Pesquisa realizada com apoio da Fapesp, processo n. 2015/25559-6. E-mail: marcello. stella1@gmail.com. 